\title{
Cardiac arrest in the OR: How are our ACLS skills?
}

\author{
Matt M. Kurrek MD, ${ }^{*}$ \\ J. Hugh Devitt MD FRCPC, * \\ Marsha Cohen MD FRCPC ${ }^{\star \dagger}$
}

Purpose: While advanced cardiac life support (ACLS) training is widely available, it is not mandatory for all anaesthetists. We hypothesised that adherence to ACLS guidelines during resuscitation of ventricular fibrillation (NFib) as assessed in a simulator environment would be poor by anaesthetists not trained in ACLS compared with those who had received training.

Methods: With approval by the ethics review board, 89 subjects participated in the study. The simulation system consisted of a computer controlled mannequin with lifelike qualities set in a mock operating room. Each subject was given a test scenario that contained several standard anaesthetic problems. A VFib cardiac arrest occurred after approximately one hour into the simulation. A perfect score (score = A) defined complete compliance with the ACLS guidelines, whereas minor deviations (score = B) included changes in energy levels, dng doses or treatment order. The failure to discontinue the anaesthetic, defibrillate or administer epinephrine were considered major deviations (score $=\mathrm{C}$ ).

Results: Eight subjects followed the ACLS guidelines ( $9 \%$, score $=$ A), while 27 subjects showed minor ( $30 \%$, score $=$ B) and 54 subjects major deviations $(61 \%$, score $=C$ ). Sixty-two of the 89 participants $(70 \%)$ had taken the ACLS course and achieved higher scores than did anaesthetists without such training $(P<0.05)$. Forty-two participants (47\%) did not discontinue the anaesthetic, $10(11 \%)$ never gave epinephrine and $5(6 \%)$ never used the defibrillator. Conclusion: Adherence to ACLS guidelines was poor. A greater proportion of subjects without previous ACIS training had deviations from protocol than did subjects who had received training. We need to consider ways to ensure that anaesthetists obtain and retain resuscitation skills according to ACLS guidelines.

Objectif : Bien que la formation en soins avancés de réanimation cardio-respiratoire soit très disponible, elle n'est pas obligatoire pour tous les anesthésistes. Notre hypothèse est que le respect des recommandations de l'ACLS durant la réanimation d'une fibrillation ventriculaire (Vfib), tel qu'évalué dans un environnement de simulateur, serait pauvre chez des anesthésistes n'ayant pas reçu la formation de l'ACLS comparativement à ceux ayant reçu cette formation.

Méthode : Après approbation du comité d'éthique, 89 sujets ont participé à l'étude. Le système de simulation consistait en un mannequin contrôlé par ordinateur présentant des caractéristiques d'un être vivant placé dans un décor de salle d'opération. Chaque sujet était soumis à un scénario contenant plusieurs problèrnes anesthésiques courants. Après environ I heure de simulation, un arrêt cardiaque par fibrillation ventriculaine survenait. Un score parfait (score $=$ A) identifiait un respect complet des recommandations de l'ACLS, alors qu'un score B identifiait des écarts mineurs tels les changements des niveaux d'énergie, les dosages de médicaments ou la séquence des traitements. Oublier de cesser l'administration d'anesthésie, de défibriller ou d'administrer de l'adrénaline étaient considérés comme des écarts majeurs et méritaient un score $C$.

Résultats : Huit sujets ont suivi les recommandations de l'ACLS (score A 9\%), alors que 27 d'entre eux ont présenté des écarts mineurs (score B 30\%) et 54 ont présenté des écarts majeurs (score C $61 \%$ ). Soixante-deux des 89 participants (70\%) avaient suivi le cours de l'ACLS et ont réussi de meilleures performances que les anesthésistes riayant pas suivi le cours $(P<0,05)$, Quarante-deux participants (47\%) ont omis de cesser l'administration de l'agent anesthésique, $10(1 \%)$ riont jamais administré d'adrénaline et $5(6 \%)$ r'ont jarnais utilisé le défibrillateur.

Conclusion : Le respect des recommandations de l'ACLS était pauvre. Une plus grande proportion des sujets rayant pas suivi l'ACLS s'écartait du protocole par rapport aux sujets ayant suivi l'ACLS. II faut trouver des moyens de s'assurer que les anesthésistes obtiennent et consenvent les habiletés de réanimation conformes aux recommandations de l'ACLS.

From the Department of Anaesthesia, Sunnybrook Health Science Centre, ${ }^{*}$ University of Toronto, 2075 Bayview Avenue, Toronto, Ontario M4N 3M5 Canada and the Clinical Epidemiology Unit, Sunnybrook Health Science Centre, and the Department of Health Administration, University of Toronto. ${ }^{\dagger}$

Address correspondence to: Dr. Matt M. Kurrek; Phone: 416-480-4799; Fax: 416-480-6039; E-mail: m.kurrek@utoronto.ca

Supported in part by a grant from PSI and a Health Canada National Scholar Award to Dr. Cohen.

Acupted for publication Nopember 16, 1997. 
$\mathrm{T}$ HE appropriate management of sudden, catastrophic intra-operative events is a critical factor for the protection of the anaesthetised patient. International guidelines for cardiac arrest treatment have been developed by the American Heart Association ${ }^{1}$ and are updated frequently. Advanced cardiac life support (ACLS) training is widely available. However current licensing and hospital credentialing requirements do not make ACLS certification mandatory for anaesthesia practitioners in most Canadian hospitals. Previous reports indicate that the management of intraoperative events is not always flawless, ${ }^{2}$ including adherence to ACLS guidelines during screen simulation. ${ }^{3}$

The recent introduction of full scale simulators allows the realistic re-creation of rare intraoperative events ${ }^{4}$ and the evaluation of resuscitative skills. We tested the hypothesis that adherence to ACLS guidelines during resuscitation of ventricular fibrillation (Vfib) would be poor by anaesthetists not trained in ACLS compared with anaesthetists with this training.

\section{Methods}

With approval by the ethics review board, 89 volunteer subjects participated in the study. Participants included university based anaesthetists, community hospital anaesthetists as well as anaesthesia residents in their final year of training.

The simulation system has been previously described ${ }^{4}$ and consists of a computer controlled mannequin (CAE- Electronics ${ }^{\mathrm{TM}}$ ) with lifelike qualities (ECG, pulse, blood pressure, saturation, heart and breath sounds) set in a completely equipped mock operating room.

Informed consent was obtained from each participant. After completion of a demographic data sheet, each subject was given a test scenario that contained several standard anaesthetic problems. A VFib cardiac arrest occurred after approximately one hour into the simulation. The VFib arrest was scripted such that the dysthythmia would not respond to early treatment such as defibrillation and drug treatment, forcing the participants to apply all stages of the treatment protocol.

Audio-video recordings of the anaesthetic as well as hard copies of the computer-generated case-log were analysed for adherence to the current ACLS guidelines for the treatment of VFib arrest. ${ }^{1}$ The criteria for adherence with guidelines was determined before subject evaluation. A perfect score (score = A) indicated complete compliance with the ACLS guidelines, whereas minor deviations (score $=\mathrm{B}$ ) included changes in the energy levels of defibrillation, drug doses or treatment order. A score of A was assigned for the sequence: discontinuation of the anaesthetic, defibrillation with 200
J, defibrillation with 200-300 J, defibrillation with 300-360 J, $1 \mathrm{mg}$ of epinephrine, defibrillation with $360 \mathrm{~J}, 1.5 \mathrm{mg} \cdot \mathrm{kg}^{-1}$ lidocaine (or bretylium $5 \mathrm{mg} \cdot \mathrm{kg}^{-1}$ or procainamide $30 \mathrm{mg} \cdot \mathrm{kg}^{-1}$ ). Whereas, a resuscitation sequence: discontinuation of the anaesthetic, defibrillation with $100 \mathrm{~J}, 0.5 \mathrm{mg}$ of epinephrine, $20 \mathrm{mg}$ lidocaine, defibrillation with $100 \mathrm{~J}$ would be assigned a score $=\mathrm{B}$. Failure to discontinue the anaesthetic, defibrillate or administer epinephrine were considered major deviations ( $\operatorname{score}=\mathrm{C}$ ).

A $\chi^{2}$ analysis was used to compare the proportion of subjects with ACLS training to those without training who adhered to the VFib ACLS guidelines.

\section{Results}

Thirty-one university staff anaesthetists (group 1), 36 community staff anaesthetists (group 2) and 22 anaesthesia residents (group 3) participated in the study (Table I). Their mean age was $40 \pm 10 \mathrm{yr}$ and 62 of the staff anaesthetists (93\% of groups 1 and 2 ) were certified by the Royal College of Physicians and Surgeons of Canada (or equivalent body) in anaesthesia. Sixty-two of the 89 participants $(70 \%)$ had taken the ACLS course $(6 \pm 4$ yr ago).

Anaesthetists with previous ACLS training achieved higher scores than those without training $(P<0.05$, Table II). Eight subjects followed the ACLS guidelines carefully ( $9 \%$, score $=\mathrm{A})$, while 27 subjects showed minor $(30 \%$, score $=\mathrm{B})$ and 54 subjects showed major deviations $(61 \%$, score $=\mathrm{C})$. Forty-two participants $(47 \%)$ did not discontinue the anaesthetic, $10(11 \%)$ never gave epinephrine and $5(6 \%)$ never used the defibrillator.

\section{Discussion}

Cardiac arrest due to ventricular fibrillation is a rare but potentially fatal complication during anaesthesia in the operating room. While some of the causes of underlying VFib arrest in the OR may not be due to

TABLE I Demographic data of the 89 participants (mean \pm SD)

\begin{tabular}{llll}
\hline & Residents & Community & University \\
\hline n & 22 & 36 & 31 \\
Age (yr) & $31 \pm 4$ & $46 \pm 10$ & $39 \pm 7$ \\
Years Practice & N/A & $15 \pm 10$ & $8 \pm 7$ \\
ACLS cert. & $95 \%$ & $56 \%$ & $68 \%$ \\
RCPSC cert. & N / A & $86 \%$ & $100 \%$ \\
\hline
\end{tabular}

TABLE II Anaesthetists with previous ACLS training achieved higher scores than those without $(P<0.05$ by chi-square)

\begin{tabular}{lll}
\hline & $\begin{array}{l}\text { ACLS trained } \\
(n=62)\end{array}$ & $\begin{array}{l}\text { non ACLS trained } \\
(n=27)\end{array}$ \\
\hline strict adherence (score = A) & $8(13 \%)$ & $0(0 \%)$ \\
minor deviations (score = B) & $22(35 \%)$ & $5(19 \%)$ \\
major deviations (score = C) & $32(52 \%)$ & $22(81 \%)$ \\
\hline
\end{tabular}


coronary artery disease, there is little reason to believe that deviations from the ACLS guidelines are indicated. The guidelines of the American Heart Association for the resuscitation of a VFib arrest recommend a well defined sequence of defibrillations along with epinephrine and lidocaine ${ }^{1}$ which should be carried out together with discontinuation of the anaesthetic.

It has previously been demonstrated that ACLS training of housestaff physicians improved resuscitation rates from in-hospital cardiac arrests. ${ }^{5}$ However, within one year of completing the ACLS course, rescuers have difficulty recalling knowledge and performing ACLS skills. ${ }^{6}$ Studies among anaesthetists in the US (where ACLS certification is often a requirement for maintenance of hospital privileges) have documented a relationship between management skills and the time since last ACLS training, ${ }^{3}$ with no anaesthetist who had ACLS training more than 24 months before evaluation being able to follow the first few steps of the guidelines. Likewise, no anaesthetist without previous training was able to carry out the resuscitation correctly. ${ }^{3} \mathrm{~A}$ small study of European anaesthetists documented inconsistent application of the ACLS guidelines, ${ }^{7}$ but the numbers in the study were small and no comment was made about the ACLS certification of their participants.

Bell et al. studied 30 anaesthetists in the Laerdal Skillmeter ResusciAnnie and found the overall resuscitation skills to be poor. ${ }^{8}$ Only $27 \%$ of the 30 anaesthetists followed the resuscitation guidelines for ventricular fibrillation correctly. They did not find a correlation between the seniority of the participants or the postgraduate qualifications and their performance level, however their numbers are too small and none of their participants was certified in ACLS.

In our study, no anaesthetist without previous ACLS training was able to follow the recommended resuscitation guidelines. The time since last ACLS training for the eight successful participants (score $=\mathrm{A}$ ) ranged from one to five years, indicating that, in contrast to above mentioned studies some of our participants with remote training were able to follow ACLS guidelines. While this finding is encouraging, the numbers are too small to allow a correlation between time since last training and score. It has previously been documented that considerable improvement in ACLS skill retention. may require quarterly reviews one year after the course. ${ }^{9}$

In view of the poor compliance with ACLS guidelines documented in our study, we should consider ways to ensure that anaesthetists obtain and retain resuscitation skills according to the published guidelines. We hope that increased awareness will lead to more self-directed study or enrollment in ACLS training or refresher courses so that compulsory enrollment would be the last resort.

\section{References}

1 Textbook of Advanced Cardiac Life Support. American Heart Association, 1994.

2 DeAnda A, Gaba DM. Role of experience in the response to simulated critical incidents. Anesth Analg 1991; 72: 308-15.

3 Schwid HA, O'Donnell D. Anesthesiologists' management of simulated critical incidents. Anesthesiology 1992; 76 : 495-501.

4 Kurrek MM, Fish KJ. Anaesthesia crisis resource management training: an intimidating concept, a rewarding experience. Can J Anaesth 1996; 43: 430-4.

5 Lowenstein SR, Sabyan, EM, Lassen CF, Kern DC. Benefits of training physicians in Advanced Cardiac Life Support. Chest 1986; 89; 512-6.

6 Lowenstein SR, Hansbrough JF, Libby LS, Hill DM, Mountain RD, Scoggin CH. Cardiopulmonary resuscitation by medical and surgical house-officers. Lancet 1981; 2: 679-81.

7 Lindekar AL, Jensen PF, and the Sophus Group. European anaesthesiologists managing unexpected ventricular fibrillation in a full-scale anesthesia simulator sophus. Anesthesiology 1994; 81: Al275.

8 Bell JH, Harrison DA, Carr B. Resuscitation skills of trainee anaestherists. Anaesthesia 1995; 50: 692-4.

9 Stros $J K$. Maintaining competency in advanced cardiac life support skills. JAMA 1983; 249: 3339-41. 